JINOTEP Vol (6) No 1 (2019): 23-29

JINOTEP (Jurnal Inovasi Teknologi Pembelajaran):

Kajian dan Riset Dalam Teknologi Pembelajaran

http://journal2.um.ac.id/index.php/jinotep/index

\title{
PENGEMBANGAN ENSIKLOPEDIA DALAM PERMAINAN ELEKTRONIK PADA KONDISI KEMAMPUAN KOGNITIF SISWA YANG BERBEDA
}

Putri Darawati Maharani, Henry Praherdhiono, Susilaningsih

Teknologi Pendidikan, Fakultas Ilmu Pendidikan, Universitas Negeri Malang

\section{Article History \\ Received:April 15, 2019 \\ Accepted:May 14, 2019 \\ Published:July 16, 2019}

\section{Keywords}

Pengembangan, ensiklopedia, permainan elektronik, kognitif

\begin{abstract}
Abstrak
Tujuan pengembangan menghasilkan produk permainan elektronik yang valid serta layak untuk siswa Kelas IV di SDN Kalipang 03 Kabupaten Blitar. Metode dalam penelitian ini adalah Research and Development. Pengembangan ini telah melalui 8 tahap, pengembangan menggunakan model Sugiyono yang telah dimodifikasi oleh peneliti. Validasi produk dilakukan terhadap ahli media dan ahli materi. Sasaran uji coba permainan elektronik yaitu siswa Kelas IV SDN Kalipang 03 Kabupaten Blitar. Berdasarkan uji coba yang dilakukan disimpulkan bahwa ensiklopedia dalam permainan elektronik yang telah dikembangkan termasuk kategori valid. Selain itu berdasarkan tes hasil belajar terhadap siswa didapatkan hasil media yang dikembangkan termasuk kategori efektif. Sehingga media permainan elektronik yang dikembangkan ini dikategorikan valid dan efektif untuk kegiatan pembelajaran.

Abstract

The purpose of development is to produce valid and feasible electronic game products for Class IV students at SDN Kalipang 03 Blitar Regency. The method in this study is Research and Development. This development has gone through eight stages, the development of using the Sugiyono model that has been modified by researchers. Product validation is carried out on media experts and material experts. The target of the electronic game trial is Class IV students of SDN Kalipang 03 Blitar Regency. Based on the trials conducted, it was concluded that the encyclopedia in electronic games that had been developed included a valid category. In addition, based on the test of learning outcomes for students, the results of the media developed included effective categories. So that the electronic game media developed is categorized as valid and effective for learning activities.
\end{abstract}

Corresponding author :

Adress: Jl. Anggrek no. 20 RT 01 RW03 kel. Kalipang, kec. Sutojayan, kab. Blitar

Instansi: Universitas Negeri Malang, Fakultas Ilmu Pendidikan, Program

Studi Teknologi Pendidikan,

E-mail: putridarawati@gmail.com
2019 Universitas Negeri Malang p-ISSN 2406-8780 e-ISSN 2654-7953 
24 JINOTEP (Jurnal Inovasi dan Teknologi Pembelajaran): Kajian dan Riset dalam Teknologi Pembelajaran Vol 6, No. 1, Oktober 2019, Hal. 23-29

\section{PENDAHULUAN}

Kemajuan teknologi saat ini berpengaruh pada pendidikan. Cara memanfaatkan pendidikan yaitu dengan menggunakan teknologi (Allen dkk., 1996). Perkembangan teknologi yang pesat, berimplikasi pula pada tersedianya fasilitas yang serba canggih baik media cetak maupun audiovisual yang digunakan sebagai sumber belajar. Salah satu sumber belajar adalah ensiklopedia (Sammut and Webb, 2011). Pembelajaran ensiklopedia saat ini tidak hanya berupa buku namun dengan adanya inovasi baru, ensiklopedia permainan elektronik berperan aktif pada dunia pendidikan. Ensiklopedia adalah bahan bacaan yang menyajikan informasi mengenai ilustrasi,gambar maupun media lain (video) (Mansyur, 2017). Informasi disertai tampilan visual dapat meningkatkan 30\% dibandingkan informasi yang dibaca dan didengar berdasarkan pengalaman Dale (asyhar, 2012:22). Dalam permainan elektronik ini ensiklopedia menjelaskan beberapa materi mengenai metamorfosis hewan disekitar. Ensiklopedia dalam permainan elektronik ini dikembangkan untuk membantu guru ketika menyampaikan materi, serta membuat suasana kelas yang tidak monoton dan membantu meningkatkan kemampuan kognitif siswa untuk memahami materi (Antonenko dan Niederhauser, 2010). Memahami merupakan tujuan pembelajaran ranah kognitif setelah mengingat, taksonomi bloom revisi Anderson dalam (Gunawan dan Palupi, 2016). Terdapat enam tingkatan dalam taksonomi Bloom, yaitu: (C1) mengingat, (C2) memahami, (C3) menerapkan, (C4) menganalisis, mengevaluasi dan (C6) mencipta. Kemampuan memahami merupakan kamampuan dasar yang penting dikuasai siswa untuk mencapai hasil belajar. Siswa tidak hanya mengingat tetapi juga memahami, oleh sabab itu pemahaman materi perlu dikuasai sejak Sekolah Dasar. Anak masih belajar dengan menggunakan objek konkret untuk mengembangkan intelektualnya. Mereka mulai sudah dapat memahami tentang menulis,

berhitung dan berkorespondensi

(mengubungkan antara bentuk dan isi) serta sudah mulai belajar berpikir secara abstrak namun masih sederhana (Desstya, 2014).

Target dalam perancangan ensiklopedia dalam permainan elektronik yaitu siswa kelas IV Sekolah Dasar. Karena banyak mengalami perkembangan, khususnya untuk segi kognitif.

Bermain menjadi kegiatan yang disenangi oleh anak-anak, begitu pula dengan orang dewasa yang senang saat bermain. MZW (2017:14) menjelaskan bahwa bermain merupakan kebutuhan primer bagi anak. Sejalan dengan Montolalu, dkk (2008:1.2) bermain merupakan kebutuhan anak. Menurut Hans Daeng dalam (Andang Ismail, 2009 :17) bermain merupakan seluruh bagian kehidupan anak dan permainan merupakan hal integral untuk proses membentuk kepribadian anak. Melalui permainan yang mendidik akan menciptakan karakter anak dan mampu melatih kamampuan berpikir kognitif pada anak. Bagi mereka mendapatkan pengetahuan baru yang memotivasi akan membantu masa depan mereka. Namun dibutuhkan cara-cara yang cukup menarik untuk mengajak anak-anak belajar sesuai kemampuan karakteristiknya yang cenderung suka bermain dan belum bisa jauh dari dunia konkret.

Pendapat Arsyad (2002) mengenai manfaat pembelajaran menggunakan media akan membantu proses pembelajaran. Penyampaian pesan dan isi materi dapat diterima dengan baik oleh siswa.

Lingkungan belajar dalam pendidikan formal akan memberikan kenyamanan kepada pengguna dalam belajar dan pembelajaran (Praherdhiono, 2014). Media pembelajaran merupakan komponen lingkungan belajar memberikan sumbangan terhadap kemampuan pengguna dalam mengakses material pembelajaran secara demokratis (Praherdhiono, 2016). Permainan elektronik merupakan permainan yang diaudio visualkan, dalam bentuk aplikasi (Giovannelli dkk., 2016). 
Permainan elektronik inilah yang kita sebut sekarang sebagai game (Gee, 2005). Permainan elektronik dijumpai pada perangkat - perangkat tertentu seperti televisi, komputer, laptop, smartphone. Adapun jenis-jenis permainan elektronik dan berbagai tujuan, salah satunya edukasi yang memiliki tujuan untuk pembelajaran. Memanfaatkan media permainan elektronik bukan lagi hal yang tidak mungkin digunakan untuk pembelajaran.

Hal ini memberikan pengaruh berbagai bidang, termasuk pada bidang pendidikan. Pendidikan dengan memanfaatkan teknologi akan mempermudah proses pembelajaran. Piaget (2013) menyebutkan, usia anak pada Sekolah Dasar (7-11 tahun) tergolong tahap perkembangan kognitif operasional konkret, dimana mereka mulai menyelesaikan masalah secara nyata. Pada tahap ini (1) anak mampu berpikir logis, (2) memahami konsep percakapan, (3) mengklarifikasi suatu objek, (4) mampu mengatasi permasalahan yang bersifat konkret dan pemecahan solusinya. (Ibda, 2015) menyimpulkan bahwa penggunaan media pembelajaran akan menjadi penting sebagai solusi mengatasi kesulitan belajar pada anak. Menurut Arsyad, (2011)kondisi tersebut bukan karena fisik yang cacat serta mental, bukan karena pengaruh dari lingkungan, hal tersebut karena faktor dari dalam individu saat mempersepsi dan proses penerimaan informasi terhadap suatu objek. Hal ini sesuai dengan fungsi media yang memberikan pengalaman kongkret pada siswa. Media pembelajaran permainan elektronik merupakan suatu hal penting dalam melengkapi keberhasilan proses pendidikan di sekolah (Smaldino dkk, 2004). Pengguna media pembelajaran konvensional seperti papan tulis dinilai dapat menimbulkan kejenuhan terhadap siswa. Terlebih lagi sumber belajarnya menggunakan buku pelajaran yang minim gambar. Dengan begitu dibutuhkan suatu pembaruan atau alternatif dalam pembelajaran, yaitu memanfaatkan media permainan elektronik yang dapat membantu guru untuk menyampaikan materi. Karena anak lebih cepat memahami pelajaran dengan cara diberikan permainan daripada membaca dan mendengarkan penjelasan guru. Berdasarkan observasi oleh peneliti di SDN Kalipang 03 Kabupaten Blitar, menemukan bahwa penggunaan media pembelajaran IPA Kelas IV Sekolah Dasar materi Daur Hidup Hewan masih sangat minim ditambah pula ada anak yang kesulitan belajar, atau sulit untuk memahami materi. Temuan di lapangan adanya laboratorium komputer digunakan pada saat mata pelajaran TIK, namun penerapan media pembelajaran saat menyampaikan materi masih sangat kurang. Pada materi Dauri Hidup Hewan, guru menggunakan metode ceramah dan hanya menggunakan media papan tulis serta buku cetak. Buku yang digunakan hanya menampilkan konsep-konsep dengan gambar yang minim, serta tidak ada tantangan untuk pembelajaran maupun suara dan video pada buku tersebut. Sehingga dalam proses pembelajaran tersebut siswa merasa bosan dan kesulitan untuk memahami materi.

Dari rumusan masalah tersebut maka muncul gagasan dari peneliti untuk mengembangkan ensiklopedia dalam permainan elektronik untuk pembelajaran. Pada materi ini peneliti mengembangkan media permainan elektronik untuk mengatasi keterbatasan aspekaspek berupa gambar, animasi serta video perkembang biakan yang belum ada pada media sebelumnya.

Melihat pentingnya media pembelajaran sebagai perantara dalam menyampaikan informasi, maka pengembangan ensiklopedia dalam permainan elektronik dijadikan sebagai salah satu solusi mengatasi permasalahan tersebut. Permasalahan tersebut diatasi dengan adanya media pembelajaran berupa permainan elektronik.

\section{Karakteristik Peserta Didik}

Karakteristik Siswa Kelas IV Sekolah Dasar Menurut Piaget (Sugihartono dkk., 2007), ada 4 tahap perkembangan berpikir pada anak yaitu tahap sensorimotorik ( 0 - 2 tahun), tahap praoperasional (2 - 7 tahun), tahap operasional 
26 JINOTEP (Jurnal Inovasi dan Teknologi Pembelajaran): Kajian dan Riset dalam Teknologi Pembelajaran Vol 6, No. 1, Oktober 2019, Hal. 23-29

konkret (7 - 11 tahun), dan tahap operasional (12 -15 tahun).

Anak dengan usia 7-11 tahun mulai menggunakan mentalnya untuk memecahkan suatu permasalahan. Aktivitas berpikir ditandai dengan kemampuan berpikir seperti mengingat,memahami dan pemecahan suatu masalah.

Karakteristik siswa SD mereka mempunyai kepribadian yang berbeda diantaranya, perbedaan dalam intelegensi, kognitif, bahasa, perkembangan pribadi dan perkembangan fisik.

Kognitif adalah kemampuan intelektual dalam berfikir, mengetahui, dan memahami. Pentingnya kognitif untuk meningkatkan kemampuan berfikir pada anak dengan cara memberikan pengalaman baru yang membuat anak senang dan dapat menerima hal tersebut dengan baik serta tidak kesulitan untuk memahaminya.

\section{METODE PENELITIAN}

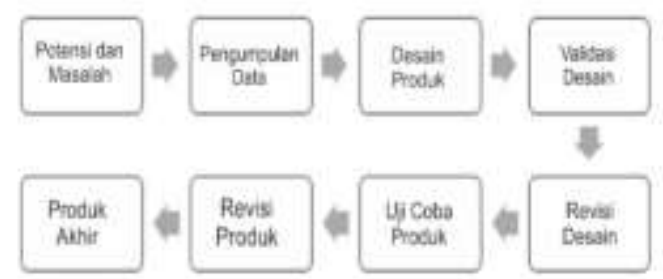

Bagan Pengembangan Model Sugiyono (2008).

Metode Penelitian yang digunakan adalah metode Research and Development (Penelitian dan Pengembangan). Adapun prosedur yang akan dilaksanakan oleh peneliti dengan memodifikasi model Sugiyono (2008). Sesuai kebutuhan pada penelitian yaitu 1.Potensi dan Masalah, 2.Pengumpulan Data, 3. Desain Produk, 4. Validasi Desain, 5. Revisi Desain Produk, 6. Uji Coba Produk, 7. Revisi Uji Coba Produk dan 8. Produk Akhir. Berikut adalah langkah - langkah penelitian model Sugiyono:

1. Potensi serta Masalah
Langkah awal yang dilakukan peneliti untuk menentukan potensi masalah dalam melakukan penelitian dan pengembangan yaitu mengkaji teori yang relevan untuk penelitian.

2. Mengumpulkan Informasi

Tahap pengumpulan informasi ini, peneliti melaksanakan observasi, mewawancarai siswa, guru dan kepala sekolah. Dari hasil informasi yang didapat, pembelajaran menggunakan media elektronik belum dimanfaatkan secara maksimal oleh guru untuk mengajar, serta pebelajar yang sukar memahami mengenai materi yang disampaikan. Pada materii daur hidup hewan untuk kelas IV Sekolah Dasar, guru masih kesulitan dalam memberikan contoh nyata untuk siswa. Selain itu, peneliti juga menganalisis kemampuan seperti: memperkirakan dana, sarana dan prasarana, tenaga dan waktuuntuk penelitian pengembangan.

\section{Desain Produk}

Peneliti membuat desain atau rancangan pengembangan yang akan dikembangkan berupa ensiklopedia dalam permainan elektronik. Sebelum memasuki tahap pembuatan permainan elektronik, dibutuhkan suatu rancangan sebagai rujukan bagi pengembang agar tahap pengembangan tidak salah arah dengan yang sudah direncanakan.

Media yang dikembangkan berupa ensiklopedia dalam permainan elektronik, dalam perancangannya meliputi storyboard. Storyboard merupakan rancangan proses pembelajaran yang di desain dan berisi informasi serta petunjuk pembelajaran. Storyboard memperlihatkan hal-hal yang harus dilakukan pebelajar selama pembelajaran dengan permainan elektronik berlangsung.

\section{Validasi Desain}

Setelah membuat produk kemudian peneliti melakukan validasi media menggunakan teknik penyebaran angket dengan 2 orang ahli. 
5. Revisi Desain Produk

Setelah melakukan validasi menurut Ahli Media dan Ahli Materi, peneliti akan melakukan perbaikan jika ada kesalahan maupun kekurangan pada produk yang dikembangkan. Revisi diperoleh dari saran ahli media dan saran ahli materi.

\section{Uji Coba Produk}

Sesudah melakukan revisi desain produk, peneliti akan melakukan uji coba di dalam di lab. komputer untuk mengetahui kelayakan permainan elektronik yang dikembangkan ini.

\section{Revisi Uji Coba produk}

Peneliti akan melakukan perbaikan menurut saran siswa dan guru jika ada kesalahan maupun kekurangan pada produk permainan elektronik yang dikembangkan ini. Saran dan komentar diperoleh dari instrumen yang diberikan pebelajar. Kemudian akan dilakukan perbaikan media melalui saran yang terkumpul.

\section{Produk akhir}

Hasil media pembejaran berupa ensiklopedia dalam permainan elektronik yang dikembangkan berdasarkan hasil dari revisi, validasi dan uji, akan disimpan ke dalam $C D$ (Compact Disk) dan Flashdisk agar mudah penggunaan dan penyimpanannya. CD akan dikemas menarik jika produk akhir dinyatakan valid dan layak digunakan untuk pembelajaran.

Penelitian ini menggunakan instrumen pengumpulan data berupa angket untuk menguji validitas media yang dihasilkan. Sedangkan untuk mengukur efektifitas produk adalah menggunakan tes hasil belajar berupa pre tes dan post tes. Proses pengumpulan data dilaksanakan langsung oleh pengembang ke lapangan.

Pengolahan data tes hasil belajar dalam penelitian ini diperoleh dengan menghitung hesil tes subjek uji coba. Uji coba yang dilakukan terhadap 30 siswa kelas IV di SDN Kalipang 03 Kabupaten Blitar. Untuk menghitung tes hasil belajar adalah dilakukan dengan cara membandingkan acuan KKM mata pelajaran IPA.

\section{HASIL}

Validasi media permainan elektronik pembelajaran dilakukan oleh ahli media, ahli materi, uji coba perseorangan, kelompok kecil, lapangan dan untuk mengukur kevalidan serta efektififitas mdia menggunakan tes hasil belajar.

Validasi ahli media, secara keseluruhan diperoleh hasil $98,33 \%$. Tingkat kelayakan sesuai dengan pendapat Arikunto (2006). Pengolahan data dan kriteria yang telah ditentukan diketahui media pembelajaran permainan elektronik yang dikembangkan termasuk ke dalam kriteria valid serta layak digunakan dalam pembelajaran.

Validasi ahli materi, secara keseluruhan diperoleh hasil 96,42\%. Berdasarkan kriteria dapat disimpulakan media pembelajaran permainan elektronik termasuk dalam kategori valid maupun layak digunakan untuk pembelajaran.

Hasil uji coba perseorangan keseluruhan diperoleh hasil 90\%. Berdasarkan hasil pengolahan data dan kriteria yang telah ditentukan, diketahui bahwa media pembelajaran permainan elektronik termasuk dalam kategori validdan layak digunakan untuk kegiatan pembelajaran.

Hasil uji coba kelompok kecil secara keseluruhan diperoleh hasil 93\%. Berdasarkan kriteria diketahui media pembelajaran permainan elektronik termasuk dalam kategori valid serta layak digunakan untuk kegiatan pembelajaran.

Hasil uji coba lapangan pada 30 siswa kelas IV SDN Kalipang 03 Kabupaten Blitar keseluruhan diperoleh hasil 91,08\%. Pengolahan data dan kriteria yang telah ditentukan, diketahui media pembelajaran permainan elektronik termasuk dalam kategori valid dan layak digunakan untukkegiatan pembelajaran.

Hasil pre tes dan post tes yang telah dilakukan siswa adanya peningkatan rata-rata 
28 JINOTEP (Jurnal Inovasi dan Teknologi Pembelajaran): Kajian dan Riset dalam Teknologi Pembelajaran Vol 6, No. 1, Oktober 2019, Hal. 23-29

dari $63,33 \%$ menjadi $83,33 \%$. Diperoleh hasil dari 30 siswa 25 siswa mengalami kenaikan nilai sedangkan 5 siswa dinyatakan belum ada peningkatan. maka dapat disimpulkan bahwa media pembelajaran permainan elektronik termasuk dalam kategori efektif.

\section{PEMBAHASAN}

Berk, (2009) mengemukakan bahwa belajar menggunakan media bergambar (video maupun audio visual) lebih baik daripada belajar dalam kondisi verbal (audio).

Penelitian yang pernah dilakukan sebelumnya dilakukan oleh Nurita Paramita (2012) dengan judul "Game Komputer untuk Mengembangkan Otak kanan Anak Autis". Dalam penelitian tersebut dinyatakan bahwa dengan adanya penegmbangan game komputer ini, maka mampu memberikan kemudahan, serta menarik minat belajar siswa.

Pada penelitian ini dikembangkan sebuah permainan elektronik dengan tema Maze yang mengadopsi dari penelitian yang telah dilakukan sebelumnya. Skenarionya pemain harus melewati jalan dengan mengambil iconicon pada level permainan dan harus memahami isi materi yang disajikan agar dapat melanjutkan ke level berikutnya. Hal ini bertujuan untuk melatih kemampuan kognitif pada siswa.

Revisi produk merupakan hasil kesimpulan dari hasil analisa data ahli media, ahli materi, dan ujicoba audiens mengenai permainan elektronik yang divalidasikan agar produk tersebut sempurna dan lebih efektif untuk kegiatan pembelajaran. Revisi produk tersebut meliputi:

\section{Tanggapan Ahli Media}

Berdasarkan instrumen ahli media, terdapat kritik maupun saran yaitu media secara umum cukup baik, valid dan dapat dilanjutkan ke tahap berikutnya, adapun yang perlu dibenahi adalah cover fisik $C D$ yang perlu dioptimalisasi, serta pada audio pembuka sebaiknya di dubbing sesuai karakter suara (sesuai visualisasi dalam tayangan).

\section{Tanggapan Ahli Materi}

Berdasarkan instrumen ahli materi, terdapat kritik maupun saran yaitu media yang digunakan sudah baik dan menarik. Secara umum materi dalam permainan elektronikk ini sudah baik dan dapat digunakan kegiatan pembelajaran.

\section{Tanggapan Audiens}

Berdasarkan instrumen dari siswa saat uji coba lapangan ada beberapa kritik maupun saran yaitu penambahan level pada permainan elektronik.

\section{SIMPULAN}

Penelitian dan pengembangan ini menghasilkan sebuah produk ensiklopedia dalam permainan elektronik materi daur hidup hewan SD kelas IV yang dikemas dalam bentuk CD (Compact Disk). Perbedaan pengembangan permainan elektronik ini dibandingkan dengan pengembangan permainan elektronik sebelumnya terletak pada video pembelajaran yang telah dianimasikan dengan karakter anak.

Hasil validasi dan ujicoba produk menunjukkan media yang dikembangkan termasuk kriteria valid, data hasil validasi oleh ahlii materi diperoleh kriteria valid, sedangkan hasil ujicoba perseorangan dipeoleh kriteria valid, hasil ujicoba kelompok kecil diperoleh kriteria valid, dan hasil ujicoba lapangan diperoleh kriteria valid.

Saran dalam pemanfaatan media permainan elektronik ini supaya pembelajaran dengan materi daur hidup hewan dapat mencapai tujuan pembelajaran, maka sebelum menggunakan, hendaknya pengguna membaca petunjuk permainan dalam media. Selama pembelajaran guru berperan sebagai fasilitator yang mengarahkan siswa ketika proses pembelajaran berlangsung. Setelah kegiatan pembelajaran selesai, guru dapat mengevaluasi pembelajaran dengan metode tanya jawab kepada siswa terkait materi. 


\section{DAFTAR RUJUKAN}

Allen, B.S., Otto, R.G., Hoffman, B., 1996. Media as lived environments: The ecological psychology of educational technology. Handb. Res. Educ. Commun. Technol. Proj. Assoc. Educ. Commun. Technol. 199-225.

Antonenko, P.D., Niederhauser, D.S., 2010. The influence of leads on cognitive load and learning in a hypertext environment. Comput. Hum. Behav. 26, 140-150.

Arikunto, S., 2006. Prosedur Penelitian Suatu Pendekatan Praktik, Ed Revisi VI. Jkt. PT Rineka Cipta 75.

Arsyad, A., 2011. Media pembelajaran. Jakarta: PT Raja Grafindo Persada.

Arsyad, A., 2002. Media pembelajaran, edisi 1. Jkt. PT Raja Graf. Persada 36.

Berk, R.A., 2009. Multimedia teaching with video clips: TV, movies, YouTube, and mtvU in the college classroom. Int. J. Technol. Teach. Learn. 5. Dari https://www.researchgate.net/profile/Ronal d Berk/publication/228349436 Multimedi a Teaching_with_Video Clips TV Movie s YouTube and mtvU in the College $\mathrm{Cl}$ assroom/links/00b7d529cc691422b000000 0/Multimedia-Teaching-with-Video-ClipsTV-Movies-YouTube-and-mtvU-in-theCollege-Classroom.pdf

DD08/ MZW. 2017. Bermain dan Begerak untuk Fokus Belajar. Kompas. Jakarta. 11 September, hlm 14.

Desstya, A. 2014. Kedudukan dan Aplikasi Pendidikan Sains di Sekolah Dasar. Profesi Pendidikan Dasar, 2(1), 193-200.

Gee, J.P., 2005. Learning by design: Good video games as learning machines. E-Learn. Digit. Media 2, 5-16.

Giovannelli, F., Giganti, F., Righi, S., Peru, A., Borgheresi, A., Zaccara, G., Viggiano, M.P., Cincotta, M., 2016. Audio-visual integration effect in lateral occipital cortex during an object recognition task: An interference pilot study. Brain Stimulat. 9, 574-576.

Gunawan, I., \& Palupi, A. R. (2016). Taksonomi Bloom-revisi ranah kognitif: kerangka landasan untuk pembelajaran, pengajaran, dan penilaian. Premiere educandum: jurnal pendidikan dasar dan pembelajaran, 2(02). Dari http://ejournal.unipma.ac.id/index.php/PE/article/v iew/50

Ibda, F., 2015. Perkembangan kognitif: teori jean piaget. Intelektualita 3.

Mansyur, M., 2017. Encyclopedia of Local Historical Figures as a Learning Source of Independent Local Content for Students of Junior High School in South Kalimantan, in: 1st International Conference on Social
Sciences Education-" Multicultural Transformation in Education, Social Sciences and Wetland Environment"(ICSSE 2017). Atlantis Press.

Montolalu, B.E.F. dkk. 2008. Bermain dan Permainan Anak. Jakarta: Universitas Terbuka.

Piaget, J., 2013. The construction of reality in the child. Routledge.

Praherdhiono, H., 2014. Convenience of Learning Environment for Student Special Education With Cyberwellness Concept. Proceeding International postdraduate University Kebangsaan Malaysia. SEAMOSEN.

Praherdhiono, H., 2016. Standar Program Pengukuran Kenyamanan Lingkungan Belajar Berbasis Ergonomi. Disertasi Dan TESIS Program Pascasarj. UM.

Sammut, C., Webb, G.I., 2011. Encyclopedia of machine learning. Springer Science \& Business Media.

Smaldino, S.E., Russell, J.D., Heinich, R., Molenda, M., 2004. Instructional media and technologies for learning. Upper Saddle River, NJ: Prentice Hall.

Sugihartono, K.N.F., Harahap, F., Setiawati, F.A., Nurhayati, S.R., 2007. Psikologi Pendidikan. Yogyak. UNY.

Sugiyono, M.P.K., 2008. kualitatif dan R\&D. Bdg. Alf. 124. 